\title{
Mulheres vitoriosas na política: estudo comparativo entre as candidaturas ao cargo de deputado estadual no RS em 2010
}

ROSANGELA SCHULZ

MARIA LÚCIA MORITZ

Resumo

O artigo pretende contribuir para a discussão do tema mulher e política ao problematizar os resultados da disputa ao cargo de deputado estadual no estado do Rio Grande do Sul/eleições 2010. A proposta é elaborar um quadro comparativo entre as candidatas e os candidatos eleitos, ou seja, através do recorte de gênero verificar similaridades e diferenças na construção de candidaturas vitoriosas em termos de votos, considerando as seguintes variáveis: recursos econômicos (despesas/receitas oficiais de campanha) e recursos políticos ou trajetória política (carreira política, redes de contatos, militância). Por fim, o intento é trabalhar estes dados à luz dos debates sobre inclusão das mulheres no campo político.

Palavras-chave: Candidaturas. Deputação Estadual. Eleições 2010.

\footnotetext{
Universidade Federal de Pelotas (Brasil)

** Universidade Federal do Rio Grande do Sul (Brasil)
} 
Victorious women in politics: a comparative study on candidacies for the state legislature in Rio Grande do Sul in 2010.

\section{Abstract}

This paper intends to contribute for the discussion on woman and politics by analyzing the results of the election for state legislators in Rio Grande do Sul in the 2010. A gender based comparative table was elaborated contrasting male and female elected candidates, in order to determine similarities and differences in the development of victorious candidacies, considering, considering the following variables: economic resources (campaign official expenses/revenues) and political resources or political trajectory (political career, networking, political activism). Our purpose was ultimately studying these data in the light of the current debates on the inclusion of women in the political scenario.

Keywords: Candidacies. State Representativeness. Elections 2010.

\section{Introdução}

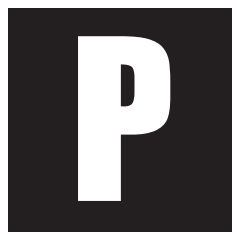

assados 15 anos da adoção das cotas nas listas partidárias e tendo duas mulheres com chances reais disputando a Presidência da República nas eleições de 2010, havia uma expectativa positiva em relação ao aumento de candidaturas femininas nos Legislativos, bem como no crescimento da representação das mulheres nos parlamentos. A primeira expectativa confirmou-se ${ }^{1}$, em que pese, longe dos $30 \%$ previstos na lei;

\footnotetext{
'Em 2006, para a Câmara dos Deputados, foram 12,7\% de candidaturas femininas e em 2010 atingiu 19,1\%. Para as Assembleias Estaduais a média foi 13,8\% no pleito de 2006 e de 22,9\% em 2010. Fonte: TSE.
} 
Sociologias, Porto Alegre, ano 17, no 39, mai/ago 2015, p. 370-402

quanto às bancadas femininas, tanto no âmbito federal como estadual, não houve avanço expressivo. Apesar de persistir a sub-representação feminina, algumas mulheres ultrapassam a barreira eleitoral e conquistam mandatos eletivos.

Independente da permanente discussão em torno da (in)eficácia das cotas, nossa proposta no presente trabalho vai em outra direção. Nosso estudo recai justamente sobre as candidaturas vitoriosas, e assim pretendemos contribuir para o debate sobre a limitada presença das mulheres no campo político, tomando como referência os resultados das eleições legislativas de 2010 no Estado do Rio Grande do Sul.

Nosso foco específico consiste nas candidaturas das mulheres e dos homens que superaram a corrida eleitoral, tornando-se parlamentares. Buscaremos responder a seguinte indagação: existem diferenças significativas entre as candidaturas femininas e masculinas que saem vitoriosas das urnas? Para dar conta desse propósito, lançaremos mão da perspectiva comparada e tomaremos como referência três variáveis que acreditamos serem importantes para explicar o sucesso eleitoral: (a) recursos políticos, (b) recursos sociais e (c) recursos econômicos. O primeiro leva em consideração a trajetória política e/ou as redes de contatos do/as candidato/ as; a segunda aborda os indicadores sócio-demográficos e, por fim, os recursos de financiamento de campanha.

O artigo está dividido em três seções: na primeira parte apresentamos uma breve discussão sobre o déficit político de gênero e (in)eficácia das cotas; a seguir oferecemos um panorama da disputa eleitoral à Assembleia Legislativa do Rio Grande do Sul em 2010 e, na terceira e última seção, a análise comparativa entre as candidaturas femininas e masculinas vitoriosas para o cargo de deputado estadual. Finalizamos com algumas notas conclusivas. 


\section{Desigualdade de gênero e sub-representação feminina}

Apesar da ampliação da atuação feminina em diferentes setores da sociedade no decorrer do século passado, as mulheres ainda estão muito distantes das instâncias decisórias, tanto na esfera pública como na arena privada. Este é um fenômeno global e significa que, em pleno século XXI, um grupo específico está alijado de influenciar as transformações sociais em todas as áreas e de exercer plenamente a sua cidadania. Chama a atenção o atual estágio da desigualdade de gênero em um campo específico: o campo político-eleitoral. De acordo com a União Interparlamen$\operatorname{tar}^{2}$ (2012) as mulheres permanecem sub-representadas em todos os continentes: seis países não possuem nenhuma mulher em seus parlamentos e, mesmo na América Latina, que ocupa o segundo lugar em termos de representação feminina, o índice não chega a 1/4 das vagas (23,8\%). Apenas nos países nórdicos elas apresentam um desempenho melhor e são detentoras de $42 \%$ dos assentos. No Brasil, a situação não difere do que é encontrado nas demais regiões do mundo e repete o panorama de desvantagem feminina, especialmente no âmbito da representação política.

A temática gênero e política tem despertado interesse dentro e fora da academia e vários pesquisadores têm se debruçado sobre o tema, produzindo investigações com vários recortes e diversas abordagens. Há, por exemplo, estudos que buscam entender as razões da sub-representação feminina e/ou apontam caminhos para sua superação, outros avaliam as ações das mulheres quando eleitas, ou ainda aqueles que analisam os impactos dessa ausência para a qualidade da democracia. Todos têm contribuído para avançar na compreensão da referida temática.

${ }^{2}$ A Inter-Parlamentary Union (IPU) é uma organização financiada com recursos públicos e em seu site disponibiliza dados sobre os parlamentos em 190 países (www.ipu.org) Acesso em 31/05/2014. 
Sociologias, Porto Alegre, ano 17, no 39, mai/ago 2015, p. 370-402

Para fins do presente trabalho, vamos enfocar o recorte da sub-representação política das mulheres e a possibilidade de superação através da adoção de cotas, e posteriormente, avançaremos em direção à análise das mulheres que superaram o obstáculo das urnas e conquistaram mandato eletivo. Cabe destacar que esse tema - sub-representação e impacto das cotas - já foi bastante analisado pela literatura e algumas respostas já foram obtidas, por isso não vamos nos deter muito nesse debate. Um consenso que permeia todas as análises é que as cotas são necessárias, mas somente elas não são suficientes para reverter a situação de desvantagem das mulheres na esfera política, em geral, e na arena parlamentar, em específico. Além da adoção dessa norma, deve-se levar em consideração se ela é cumprida, ou não, e que sanções estão previstas para este caso. Mesmo com avaliação positiva sobre a implementação das cotas, ainda não temos trabalhos que comprovem uma correlação direta entre maior oferta e resultado positivo, ou seja, se mais candidatas concorrendo resultará necessariamente em mais mulheres eleitas.

Entre as várias abordagens sobre a eficácia, ou não, das ações afirmativas, podemos destacar o modelo institucionalista. Este aponta as características do sistema partidário e eleitoral como favorecedor, em maior ou menor grau, da presença feminina na política. Dentre os poucos consensos existentes, essa vertente destaca o sistema proporcional associado ao sistema pluripartidário como características das mais favoráveis à eleição das mulheres, e as siglas de esquerda sendo mais receptivas às candidaturas femininas ${ }^{3}$.

Entretanto, não há convergência quanto ao efeito de outros aspectos institucionais, como o tipo de lista (aberta ou fechada) e a magnitude dos distritos (grandes ou pequenos), enquanto favorecedores de candidatu-

${ }^{3}$ Entre as autoras que destacam essa associação estão Schmidt e Araújo (2004), Araújo (2006a; 2006b; 2009); Archenti e Tula (2008). 
ras femininas. Em trabalho anterior ${ }^{4}$ testamos um conjunto de variáveis institucionais (magnitude dos distritos, tamanho e ideologia dos partidos) e constatamos que algumas assertivas encontradas na literatura não são integralmente válidas para o caso brasileiro. Com base no universo das eleitas para o cargo de deputada federal em 2010, identificamos que, proporcionalmente, as mulheres se elegeram em distritos de média magnitude, em pequenos partidos e à esquerda do espectro ideológico. A manutenção dessa conclusão carece de mais estudos longitudinais.

Às variáveis já citadas, devem-se agregar outras que permitam associações mais consistentes e que possibilitem comprovação empírica robusta sobre a relação entre o arcabouço institucional e seu impacto sobre a reserva de vagas por gênero. É sabido que a desvantagem política das mulheres é multicausal e para sua melhor compreensão devemos olhar para além da matriz institucionalista e incorporar outros aspectos, tais como recrutamento partidário, financiamento de campanha, rede de apoio, trajetória política e fatores de ordem sócio-demográfica, pois a disputa eleitoral também é impactada por variáveis externas a este processo ${ }^{5}$.

Como já salientado, a análise sobre o déficit de representação feminina deve ir além do desenho institucional; daí que outros autores apontam fatores de ordem cultural e econômica impactando as mulheres de diferentes formas e em vários momentos de sua vida. Por exemplo, quando decidem filiar-se a um partido, ao se candidatar a um cargo eletivo e no momento inicial da carreira política - quando alcançam sucesso eleitoral e conquistam representação - até a consolidação dessa trajetória.

${ }^{4}$ Paper de nossa autoria, intitulado "Mulheres vitoriosas na política: estudo comparativo entre as deputadas federias do Brasil e do Uruguai (2009 - 2014)" e apresentado no XXIX Congresso da ALAS - Chile/2013.

${ }^{5}$ Speck e Sacchet (2012) analisaram o impacto das questões sociogeoeconômicas nas candidaturas femininas no pleito de 2010, enfocando três variáveis: bens, instrução e ocupação. 
Sociologias, Porto Alegre, ano 17, no 39, mai/ago 2015, p. 370-402

Clara Araújo (2009) aponta o peso e a importância dos aspectos socioeconômicos, culturais e políticos (institucional) na decisão das mulheres de se candidatarem a postos eletivos:

Os culturais destacam os valores mais gerais que influenciam uma dada sociedade, bem como uma cultura de gênero mais ou menos igualitarista (NORRIS, 1993). Os sócioeconômicos remetem a alguns indicadores, como escolaridade, renda e emprego. Já a dimensão política é tratada mais do ponto de vista das instituições partidárias e eleitorais e dos tipos de sistemas de representação (JONES, 2008, p.79). Não há, contudo, consenso sobre o peso de cada um deles na definição das disposições e das chances das mulheres para concorrer e se eleger a um cargo legislativo (ARAÚJO, 2009, p. 25).

Também Miguel e Biroli (2010) participam do debate sobre as possíveis razões da sub-representação política das mulheres, mas a partir de outra perspectiva. Os autores destacam três eixos explicativos não-institucionais: (a) o caráter patriarcal subjacente às instituições políticas liberais; (b) os padrões culturais e de socialização; e (c) os constrangimentos estruturais à participação política das mulheres. O caráter cultural refere-se à construção do espaço político como masculino e dessa forma inibidor do surgimento da "ambição política" entre as mulheres. Também Speck e Sacchet (2012) destacam a importância da "ambição" na perspectiva eleitoral feminina, de acordo com os autores, as mulheres seriam também educadas para uma vida menos autônoma e distante da cultura da ambição necessária para entrar na disputa política (SPECK e SACCHET, 2012, p.168).

Em relação aos constrangimentos estruturais Miguel e Biroli (2010) ainda argumentam que, via de regra, as mulheres têm menos acesso aos recursos econômicos e menos tempo livre do que os homens para se dedicar à política. Estudos eleitorais anteriores têm destacado que, para participar da política e disputar cargos eletivos, independentemente do gênero, são necessários três tipos de recursos: dinheiro, tempo livre e 
Sociologias, Porto Alegre, ano 17, no 39, mai/ago 2015, p. 370-402

rede de contatos. A falta de um ou mais destes recursos afeta diretamente todos aqueles que ingressam na carreira política, mas ainda faltam estudos comparativos que avaliem como as candidaturas femininas são afetadas por essas três variáveis e quais são os seus impactos no desempenho final das candidatas.

A importância do recurso financeiro em disputas eleitorais vem sendo analisada por vários autores, ora de forma independente ora associado a outras variáveis ${ }^{6}$. Independentemente da abordagem, os resultados apurados convergem para um mesmo ponto: "dinheiro faz diferença" ${ }^{\text {"7 }}$, entretanto essa variável sozinha não consegue explicar o sucesso ou insucesso de uma candidatura num processo eleitoral. Supõe-se que candidato/as com maior capital financeiro apresentem melhor desempenho nas urnas, sendo assim, as mulheres, dada sua entrada tardia na arena político-eleitoral, teriam menor capacidade de arrecadar fundos, consequentemente, elas estariam em desvantagem frente a uma disputa eleitoral e assim, teriam suas chances de vitória diminuídas. Esse círculo vicioso agravaria ainda mais a desigualdade de gênero na arena política. Entretanto, Miguel e Biroli afirmam que os dados oficiais em nosso país mostram um quadro diferente do esperado em relação a gastos de campanha:

[...] No Brasil, os dados oficiais mostram gastos de campanha similares para homens e mulheres para a Câmara dos Deputados em 2006, com elas, em média, despendendo $3 \%$ a mais do que eles. No caso das assembleias estaduais, na mesma eleição, elas gastam 35\% a menos, em média, em suas campanhas (Idem, p. 669).

\footnotetext{
${ }^{6}$ Os pesquisadores que vem abordando o tema financiamento de campanha são Araújo e Borges (2012); Araújo (2013); Lemos, Marcelino e Pederiva (2010); Sacchet e Speck (2010b; 2012); Sacchet (2011); Samuels (2005).

${ }^{7}$ De acordo com Lemos et al. "os candidatos vencedores gastaram, em média, 5 vezes mais do que os adversários". Porque dinheiro importa: a dinâmica das contribuições eleitorais para o Congresso Nacional em 2002 e 2006. Opinião Pública, Campinas, Vol.16, n.2, novembro/2010, pp. 374.
} 
Sociologias, Porto Alegre, ano 17, no 39, mai/ago 2015, p. 370-402

Já que estamos assumindo que dinheiro potencializa as chances de vitória de uma candidatura, independentemente do gênero, precisamos entender melhor a afirmação anterior. Talvez o caminho para sua compreensão passe pela incorporação de outra variável à análise: mandato anterior. Ou seja, o lançamento de uma candidatura à Câmara dos Deputados geralmente só ocorre depois de uma carreira política minimamente consolidada e, dessa forma, homens e mulheres estão em um patamar de concorrência muito próximos. Ser representante dá uma grande visibilidade no decorrer do exercício do mandato, especialmente na mídia e junto às bases; sendo assim, estão em vantagem frente aos novatos/sem mandato. Quando a disputa se realiza no âmbito estadual, elas gastam menos do que os homens, muito provavelmente, porque arrecadam menos do que eles devido a sua menor capacidade arrecadatória. Voltaremos a esse ponto na próxima seção.

Ainda abordando o aspecto recurso econômico temos a contribuição de Clara Araújo (2013), Teresa Sacchet e Bruno Speck (2012). Esses dois últimos apresentaram suas conclusões no livro Mulheres nas eleições $2010^{8}$, obra que é resultado do esforço de vários pesquisadores e apresenta um extenso panorama interpretativo da disputa eleitoral, enfocando o desempenho feminino em todo o país na última eleição geral. Os referidos autores tratam especificamente da questão financeira em dois capítulos. No primeiro, apresentam uma análise comparativa das condições socioeconômicas das candidaturas de mulheres e homens; no segundo focam no financiamento de campanha e desempenho eleitoral. Sacchet e Speck (2012) concluem que patrimônio financeiro, nível educacional e experiência profissional e política têm impacto no sucesso eleitoral, em suas palavras:

${ }^{8}$ Livro organizado por ALVES, J.; PINTO, C. e JORDÃO, F. São Paulo: ABCP/Secretaria Especial para as Mulheres, 2012; $520 \mathrm{p}$. 
Sociologias, Porto Alegre, ano 17, no 39, mai/ago 2015, p. 370-402

Ter herdado ou acumulado grandes riquezas não é garantia de sucesso nas urnas, mas aumenta em cinco vezes as chances de se eleger. A instrução não possui o mesmo impacto sobre o sucesso eleitoral, porém, quem tiver diploma universitário aumenta em $50 \%$ as chances de obter êxito nas eleições em relação aos demais candidatos. Finalmente, a ocupação no momento da disputa eleitoral é decisiva para o sucesso nas urnas. A categoria que mais se destaca refere-se aos políticos em cargos eleitos que disputam um novo mandato (Idem, p. 204).

A citação destacada reforça a relação entre aporte financeiro e desempenho eleitoral e vem ao encontro das conclusões de outros pesquisadores como Lemos et al. (2010) que, inclusive, acharam a mesma proporcionalidade nas eleições de 2002 e 2006 para o cargo de deputado federal, mas agregaram, além do recurso econômico, outras variáveis intervenientes para explicar o sucesso nas urnas.

No segundo artigo, os autores ressaltam a importância dos capitais político e social do candidato para a sua campanha, com destaque para os recursos financeiros. Entretanto, Sacchet e Speck salientam que o aspecto econômico não influencia apenas o resultado eleitoral, mas também o processo de definição das candidaturas (SACCHET e SPECK, 2010, p. 419). Ou seja, as mulheres, antes mesmo de entrarem na disputa por um mandato eletivo, já estão em desvantagem frente aos homens, neste caso, desigualdade econômica. Como na eleição proporcional os próprios candidatos têm que viabilizar economicamente suas campanhas, é fundamental a sua capacidade de arrecadação e esta advém, em boa parte, dos contatos e redes estabelecidas. Geralmente as mulheres são novatas nesse tipo de disputa, elas têm menos dinheiro para investir na sua campanha e menor capacidade de arrecadação.

Quanto às redes de contatos, estudos que tratam de candidaturas femininas destacam a importância das redes de apoio herdadas de pais, 
Sociologias, Porto Alegre, ano 17, no 39, mai/ago 2015, p. 370-402

irmãos ou maridos e mostram que, no Brasil, o capital familiar foi identificado como origem do capital político de 40,8\% das deputadas federais brasileiras de 1987 a 2002 (MIGUEL e BIROLI, 2010, p. 668). Porém, como bem ressaltam os autores, a ausência de estudos comparativos não permite avaliar o quanto o fenômeno é uma especificidade feminina. $\mathrm{O}$ terceiro recurso - tempo livre - embora fundamental na discussão sobre sub-representação feminina não será abordado no momento, pois necessita de informações que a pesquisa em pauta não contemplou.

Assim, reafirmamos que o sucesso ou insucesso em uma campanha eleitoral, tanto para homens como para mulheres, é multicausal e depende de muitas variáveis, com destaque para o que, no presente trabalho, denominamos de recursos políticos (trajetória política e/ou as redes de contatos), recursos sociais e recursos econômicos disponíveis, que juntos compõem o capital político acumulado ao longo da carreira política. Como já foi destacado, as mulheres entram no processo eleitoral em condições desiguais e, apesar do cenário de desvantagem, algumas conseguem se destacar e ultrapassam a barreira das urnas, construindo uma carreira política eleitoral vitoriosa.

\section{O panorama eleitoral no Legislativo do Rio Grande do Sul (RS)}

Nas eleições de 2010, mais de 200 mulheres apresentaram-se para a disputa aos cargos majoritário e proporcional no RS. Destas, 133 disputavam o cargo de Deputado Estadual. Em que pese ter havido aumento nas candidaturas femininas para a Assembleia Legislativa em 2010 (24,4\%), comparado ao pleito de $2006(13,8 \%)$, as mulheres não atingiram a cota mínima de 30\% exigida por lei. 
Sociologias, Porto Alegre, ano 17, no 39, mai/ago 2015, p. 370-402

Tabela 1. Eleições para o Legislativo Estadual 2006 e 2010: Distribuição dos Candidatos Cargo x Gênero/RS

\begin{tabular}{l|c|c|c|c}
\hline \multirow{2}{*}{ Pleito 2010 } & \multicolumn{2}{|c|}{ Candidaturas } & \multicolumn{2}{c}{ Eleitos } \\
\cline { 2 - 5 } & $\mathbf{N}$ & $\%$ & $\mathbf{N}$ & $\%$ \\
\hline Homens & 411 & $75,6 \%$ & 47 & $85,5 \%$ \\
\hline Mulheres & 133 & $24,4 \%$ & 08 & $14,5 \%$ \\
\hline Total & 544 & $100 \%$ & 55 & $100 \%$ \\
\hline
\end{tabular}

Fonte: Site TSE (www.tse.gov.br)

O crescimento quantitativo de candidaturas femininas gerou a expectativa de que a maior oferta de candidatas se traduzisse em maior número de eleitas. No caso da Assembleia Legislativa, a expectativa foi parcialmente atingida, pois houve crescimento da bancada feminina com incremento de três novas deputadas. Assim, dentre as 55 vagas disponíveis para a Assembleia Legislativa do RS, oito foram ocupadas por mulheres (tabela 1). Entre as eleitas, é mister chamar a atenção para dois pontos: ocorrência de reeleição das mulheres, com cinco candidatas reconduzidas e o desempenho nas urnas da candidata Silvana Covatti, concorrendo à reeleição pelo $\mathrm{PP}$, candidata mais votada entre todos os candidatos ao Legislativo estadual.

A tabela 2 apresenta o número de vagas conquistadas por cada partido no Legislativo estadual em 2010 e a respectiva distribuição entre os dois gêneros. 
Sociologias, Porto Alegre, ano 17, no 39, mai/ago 2015, p. 370-402

Tabela 2. Eleições 2010: Partidos x Gênero - Assembleia Legislativa/RS

\begin{tabular}{l|c|c|c|c|c}
\hline \multirow{2}{*}{\multicolumn{1}{c|}{ Partido }} & \multirow{2}{*}{ Total } & \multicolumn{2}{c|}{ Mulheres } & \multicolumn{2}{c}{ Homens } \\
\cline { 3 - 6 } & & $\mathbf{N}$ & $\mathbf{\%}$ & $\mathbf{N}$ & $\%$ \\
\hline PT & 14 & 4 & $28,6 \%$ & 10 & $71,2 \%$ \\
\hline PMDB & 8 & 1 & $12,5 \%$ & 7 & $87,5 \%$ \\
\hline PDT & 7 & 1 & $14,3 \%$ & 6 & $85,7 \%$ \\
\hline PP & 7 & 1 & $14,3 \%$ & 6 & $85,7 \%$ \\
\hline PTB & 6 & 0 & - & 6 & $100 \%$ \\
\hline PSDB & 5 & 1 & $20 \%$ & 4 & $80 \%$ \\
\hline PSB & 3 & 0 & - & 3 & $100 \%$ \\
\hline PPS & 2 & 0 & - & 2 & $100 \%$ \\
\hline PRB/DEM/PCdoB & $1(3)$ & 0 & - & $1(3)$ & $100 \%$ \\
\hline Total & $\mathbf{5 5}$ & $\mathbf{8}$ & $\mathbf{1 4 , 5} \%$ & $\mathbf{4 7}$ & $\mathbf{8 5 , 5} \%$ \\
\hline
\end{tabular}

Fonte: Site TRE/RS (www.tre.gov.br)

Os dados são bastante reveladores da disparidade entre homens e mulheres em termos de representação política no RS: as deputadas são detentoras de apenas $14,5 \%$ dos assentos, ou seja, a bancada feminina é seis vezes menor do que a bancada masculina. Em relação aos partidos, percebe-se que seis legendas não elegeram nenhuma mulher entre as 11 siglas que obtiveram representação parlamentar. Chama a atenção o PTB, quarta maior bancada, e não elegeu nenhuma deputada. O PT conquistou o maior número de vagas (14) e também foi o partido que elegeu mais mulheres (4).

Os dados abaixo permitem visualizar a distribuição dos votos, por faixa de votação, dos 411 homens e das 133 mulheres que disputaram uma vaga no Legislativo estadual, independentemente de terem sido eleitos, ou não. 
Sociologias, Porto Alegre, ano 17, no 39, mai/ago 2015, p. 370-402

Tabela 3. Eleições 2010: Votação x Gênero - Assembleia Legislativa/RS

\begin{tabular}{l|c|c|c|c}
\hline \multirow{2}{*}{ Faixa de votação } & \multicolumn{2}{|c|}{ Mulheres } & \multicolumn{2}{c}{ Homens } \\
\cline { 2 - 5 } & $\mathbf{N}$ & $\mathbf{\%}$ & $\mathbf{N}$ & $\%$ \\
\hline 50.000 a 99.999 votos & 2 & $1,5 \%$ & 16 & $3,9 \%$ \\
\hline 20.000 a 49.999 votos & 13 & $9,8 \%$ & 67 & $16,3 \%$ \\
\hline 10.000 a 19.999 votos & 08 & $6,0 \%$ & 51 & $12,4 \%$ \\
\hline 5.000 a 9.999 votos & 15 & $11,3 \%$ & 62 & $15,1 \%$ \\
\hline 1.000 a 4.999 votos & 23 & $17,3 \%$ & 110 & $26,8 \%$ \\
\hline Até 999 votos & 72 & $54,1 \%$ & 105 & $25,5 \%$ \\
\hline Total & $\mathbf{1 3 3}$ & $\mathbf{1 0 0} \%$ & $\mathbf{4 1 1}$ & $\mathbf{1 0 0} \%$ \\
\hline
\end{tabular}

Fonte: Site TSE (www.tse.gov.br)

Examinando-se as duas pontas desta tabela, os mais e os menos votados, verifica-se uma inversão de posições: os homens mais votados (acima de 20 mil votos) chegam a 20,2\%, percentualmente são quase o dobro das mulheres $(11,3 \%)$. Já na ponta inferior, onde estão os menos votados e que obtiveram abaixo de mil votos, os candidatos são a metade $(25,5 \%)$ das candidaturas femininas $(54,1 \%)$. Esses dados sugerem que há muito mais candidatos homens efetivamente disputando vagas à Assembleia Legislativa do que candidatas mulheres.

O quadro geral sobre o desempenho das candidaturas femininas ao Legislativo do Rio Grande do Sul vem ao encontro das posições comentadas no início desta seção. Poucas são as mulheres que se candidatam, menor ainda é o número de mulheres que conseguem alcançar a votação necessária para assumir uma cadeira legislativa. A próxima seção do artigo propõe um quadro comparativo das candidaturas vitoriosas de homens e mulheres. 
Sociologias, Porto Alegre, ano 17, no 39, mai/ago 2015, p. 370-402

\section{Candidaturas bem sucedidas à deputação estadual do RS}

Como o objetivo é analisar as candidaturas bem sucedidas, ou seja, aquelas vitoriosas, optamos por investigar todos os 55 candidatos eleitos, apesar da diferença numérica entre homens e mulheres - foram oito candidatas eleitas e 47 candidatos eleitos. Assim, acreditamos cumprir a proposta de averiguar as diferenças e as similaridades nas candidaturas bem sucedidas de homens e mulheres. Para compreender quem são este/as candidato/as e o seu sucesso nas urnas, partiremos dos dados constantes na ficha de inscrição junto ao Tribunal Regional Eleitoral/RS; a prestação de contas apresentada ao TRE/RS e as informações constantes nos sites pessoais dos candidato/as e no site da Assembléia Legislativa.

Como destacado na introdução, o sucesso ou insucesso em uma campanha eleitoral, tanto para homens como para mulheres, depende de muitas variáveis, com destaque para: redes de contatos ou trajetória política e recursos econômicos/financiamento de campanha.

A tabela a seguir apresenta os 55 eleito/as selecionados para a análise. Além dos nomes, consta a posição final na lista de eleitos, a respectiva votação e a arrecadação (ou despesa) de campanha. Como já foi dito, o PT é o partido com a maior bancada (14) na Assembléia do RS e a legenda que elegeu mais mulheres (4). A maioria das deputadas eleitas para a Assembléia gaúcha é oriunda de partidos de esquerda (PT e PDT), a vinculação das eleitas com este campo ideológico tem se constituído em uma constante nas eleições brasileiras, não sendo uma particularidade do Rio Grande do Sul. 
Sociologias, Porto Alegre, ano 17, no 39, mai/ago 2015, p. 370-402

Tabela 4. Resultado Eleições Legislativas 2010/RS: Candidatos/as na posição final na lista de eleitos $x$ Votos $x$ Despesas de campanha

\begin{tabular}{|c|c|c|}
\hline Candidato/as na Posição final na lista de eleitos & Total de Votos & Total de Despesas (R\$) \\
\hline 1‥ Silvana Covatti (PP) & 85.604 & $335.407,24$ \\
\hline 2‥ Marco Alba (PMDB) & 82.269 & $423.289,65$ \\
\hline 3․ Pedro Westphalen (PP) & 72.910 & $587.085,84$ \\
\hline 4ㅇ. Edegar Pretto (PT) & 69.233 & $133.405,01$ \\
\hline 5․ Lucas Redecker (PSDB) & 69.043 & $361.050,56$ \\
\hline 6‥ Edson Brum (PMDB) & 67.397 & $409.920,99$ \\
\hline 7‥ Heitor Schuch (PSB) & 66.591 & $162.300,00$ \\
\hline 8‥ Raul Pont (PT) & 65.430 & $277.404,97$ \\
\hline 9o. Luiz Fernando Mainardi (PT) & 64.375 & $450.498,53$ \\
\hline 10‥Valdeci Oliveira (PT) & 64.163 & $231.096,57$ \\
\hline 11‥ Márcio Biolchi (PMDB) & 63.932 & $1.003 .669,87$ \\
\hline 12‥ Paulo Odone (PPS) & 63.919 & $287.770,34$ \\
\hline 13ㅇ. Juliana Brizola (PDT) & 61.305 & $343.223,19$ \\
\hline 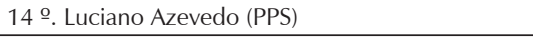 & 59.466 & $201.453,41$ \\
\hline 15 ‥ Antônio Carlos Gomes (PRB) & 59.144 & $305.374,98$ \\
\hline 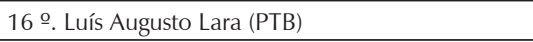 & 57.936 & $420.607,83$ \\
\hline $17 \stackrel{\text { o. Giovani Feltes (PMDB) }}{ }$ & 55.276 & $268.110,85$ \\
\hline 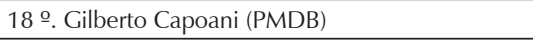 & 53.050 & $349.939,52$ \\
\hline 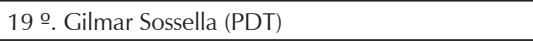 & 49.510 & $314.092,91$ \\
\hline 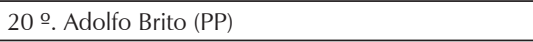 & 48.422 & $120.680,75$ \\
\hline 21‥ Stela Farias (PT) & 48.070 & $203.555,19$ \\
\hline 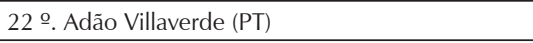 & 47.758 & $677.586,66$ \\
\hline $23 \stackrel{2}{2}$. Daniel Bordignon (PT) & 46.828 & $337.291,90$ \\
\hline 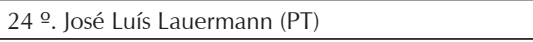 & 46.541 & $551.969,56$ \\
\hline $25 \stackrel{2}{2}$. Frederico Antunes (PP) & 46.537 & $554.078,34$ \\
\hline 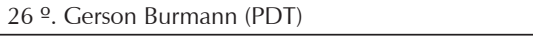 & 46.363 & $156.492,23$ \\
\hline 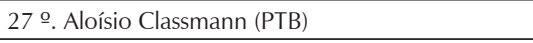 & 46.252 & $289.531,67$ \\
\hline $28 \stackrel{\text {. Alexandre Postal (PMDB) }}{ }$ & 45.631 & $122.363,00$ \\
\hline 29o. Miriam Marroni (PT) & 45.450 & $139.393,00$ \\
\hline 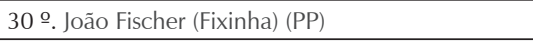 & 44.798 & $609.412,85$ \\
\hline 31‥ Marisa Formolo (PT) & 43.860 & $200.723,74$ \\
\hline 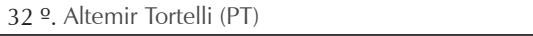 & 43.484 & $213.002,65$ \\
\hline 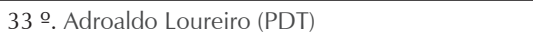 & 43.266 & $432.989,47$ \\
\hline
\end{tabular}

http://dx.doi.org/10.1590/15174522-017003921 
Continuação

\begin{tabular}{|c|c|c|}
\hline 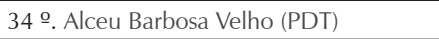 & 43.120 & $122.912,65$ \\
\hline 35 o. Francisco Gorski - Chicão (PP) ${ }^{1}$ & 43.012 & $266.200,17$ \\
\hline 36. Diogo Paz Bier - Mano Changes (PP) & 42.220 & $424.031,50$ \\
\hline 37ㅇ. Maria Helena Sartori (PMDB) & 38.958 & $323.476,52$ \\
\hline 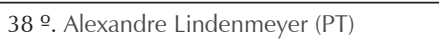 & 38.740 & $68.567,00$ \\
\hline 39o. Ana Affonso (PT) & 38.525 & $509.684,72$ \\
\hline 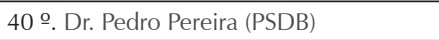 & 38.268 & $138.852,08$ \\
\hline 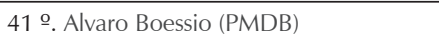 & 37.971 & $105.125,20$ \\
\hline 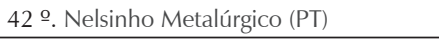 & 37.483 & $663.093,15$ \\
\hline 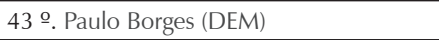 & 36.751 & $117.331,85$ \\
\hline 44 o. Adilson Troca (PSDB) & 36.611 & $184.636,42$ \\
\hline 45 o. Diógenes Basegio (PDT) & 36.071 & $258.430,70$ \\
\hline $46^{\circ}$. Ciro Simoni (PDT) & 35.477 & $306.111,34$ \\
\hline 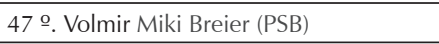 & 35.457 & $213.960,73$ \\
\hline 48 o. Ronaldo Santini (PTB) & 35.029 & $252.190,74$ \\
\hline 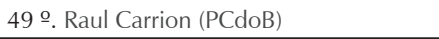 & 34.791 & $268.018,11$ \\
\hline 50‥ Zila Breitenbach (PSDB) & 34.676 & $362.259,83$ \\
\hline $51 \stackrel{\circ}{2}$. Jorge Pozzobom (PSDB) & 33.474 & $174.227,84$ \\
\hline 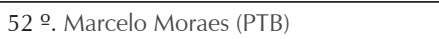 & 32.535 & $67.134,49$ \\
\hline 53 o. José Francisco Sperotto (PTB) & 32.458 & $235.842,83$ \\
\hline 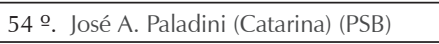 & 32.035 & $94.135,00$ \\
\hline 55ㅇ. José Antônio (Cassiá) Carpes(PTB) & 30.817 & $259.000,89$ \\
\hline
\end{tabular}

Fonte: Site TSE (www.tse.gov.br)

Na contabilização dos votos para a Assembleia Legislativa, alguns dados chamam a atenção, além do crescimento da bancada feminina: as oito eleitas fizeram votações expressivas, sendo que duas delas foram campeãs de voto: Silvana Covatti (PP) foi a deputada estadual mais votada entre os 55 eleitos; e Juliana Brizola (PDT) teve o melhor desempenho entre seus colegas de partido. 
Sociologias, Porto Alegre, ano 17, no 39, mai/ago 2015, p. 370-402

Analisando mais detidamente as oito mulheres que se elegeram deputadas estaduais, constatamos que cinco buscavam reeleição e três eram vereadoras em grandes municípios do RS ${ }^{9}$. Todas elas possuem fortes vínculos partidários e sempre estiveram filiadas a um mesmo partido: quatro no PT, uma no PDT, uma no PP, uma no PMDB e uma no PSDB.

Para elaborar a trajetória política dos candidato/as selecionado/as para análise, tentando observar as redes de contato que possibilitam a construção do capital político e consequentemente, a carreira bem sucedida, optamos por traçar o perfil sócio-demográfico do grupo ora analisado através de um conjunto de variáveis: idade, escolaridade e profissão. Complementando estes dados, na sequência apresentamos uma breve biografia política de cada um dos candidato/as buscando detectar: tipos de capital que possibilitaram a carreira, filiação partidária, mandatos anteriores, etc.

Tabela 5. Distribuição Gênero x Faixa Etária

\begin{tabular}{l|c|c|c|c}
\hline \multirow{2}{*}{ Faixa Etária (em 2010) } & \multicolumn{2}{|c|}{ Homens } & \multicolumn{2}{c}{ Mulheres } \\
\cline { 2 - 5 } & $\mathbf{N}$ & $\%$ & $\mathbf{N}$ & $\%$ \\
\hline $\mathbf{2 5}$ a 34 anos & 03 & $6,4 \%$ & - & - \\
\hline $\mathbf{3 5}$ a 44 anos & 11 & $23,4 \%$ & 02 & $25 \%$ \\
\hline $\mathbf{4 5}$ a 59 anos & 26 & $55,3 \%$ & 04 & $50 \%$ \\
\hline $\mathbf{6 0}$ a 69 anos & 07 & $14,9 \%$ & 02 & $25 \%$ \\
\hline Total & 47 & $100 \%$ & 08 & $100 \%$ \\
\hline
\end{tabular}

Fonte: Site TSE (www.tse.jus.br)

$\overline{{ }^{9} \mathrm{As} \text { vereadoras que }}$ concorreram a Deputada Estadual e se elegeram foram: Juliana Brizola, vereadora em Porto Alegre, Miriam Marroni, representante na Câmara Municipal de Pelotas e Ana Affonso, vereadora em São Leopoldo. 
Sociologias, Porto Alegre, ano 17, no 39, mai/ago 2015, p. 370-402

É muito similar a distribuição da idade dos candidato/as, com a maioria concentrando-se na faixa entre 45 e 59 anos, o que pode ser considerado um perfil de indivíduos "maduros". A idade mais tardia revelada deve-se ao fato de a maioria dos eleito/as já ser detentor/a de mandato, ou seja, neste grupo de 55 deputado/as estaduais, 36 buscavam a reeleição (32 homens e 04 mulheres). Portanto, os candidatos que conquistaram assento no Parlamento estadual, majoritariamente, já possuem uma longa trajetória na vida política.

Em relação ao estado civil, o resultado apurado também é semeIhante entre os dois grupos: a maioria dos candidato/as é casado/a, o que reforça o "perfil de maturidade" encontrado na variável idade. O estado civil assume especial importância, na medida em que vai ao encontro da afirmação dos autores Miguel e Biroli, destacados na primeira seção, sobre a dificuldade das mulheres em se dedicarem integralmente à carreira política. Existem "imperativos familiares" dos quais elas também devem dar conta e que acabam por afetar o seu desempenho na vida pública.

Tabela 6. Distribuição Gênero x Estado Civil

\begin{tabular}{l|c|c|c|c}
\hline \multirow{2}{*}{ Estado Civil } & \multicolumn{2}{|c|}{ Homens } & \multicolumn{2}{c}{ Mulheres } \\
\cline { 2 - 5 } & $\mathbf{N}$ & $\%$ & $\mathbf{N}$ & $\%$ \\
\hline Solteiro(a) & 05 & $10,6 \%$ & 01 & $12,5 \%$ \\
\hline Casado(a) & 37 & $78,8 \%$ & 06 & $75 \%$ \\
\hline Viúvo(a) & - & - & 01 & $12,5 \%$ \\
\hline Sep/Divorciado(a) & 05 & $10,6 \%$ & - & - \\
\hline Total & 47 & $100 \%$ & 08 & $100 \%$ \\
\hline
\end{tabular}

Fonte: Site TSE (www.tse.jus.br) 
Sociologias, Porto Alegre, ano 17, no 39, mai/ago 2015, p. 370-402

A variável escolaridade também chama a atenção, pois a imensa maioria dos candidato/as frequentou a universidade, mesmo que não a tenha concluído, conforme explicita a próxima tabela.

Tabela 7. Distribuição Gênero x Escolaridade

\begin{tabular}{l|c|c|c|c}
\hline \multirow{2}{*}{ Escolaridade } & \multicolumn{2}{|c|}{ Homens } & \multicolumn{2}{c}{ Mulheres } \\
\cline { 2 - 5 } & $\mathbf{N}$ & $\%$ & $\mathbf{N}$ & $\%$ \\
\hline Ens. Médio Incompleto & 01 & $2,1 \%$ & - & - \\
\hline Ens. Médio Completo & 11 & $23,4 \%$ & - & - \\
\hline Ens. Superior Incompleto & 07 & $14,9 \%$ & 02 & $25 \%$ \\
\hline Ens. Superior Completo & 28 & $59,6 \%$ & 06 & $75 \%$ \\
\hline Total & 47 & $100 \%$ & 08 & $100 \%$ \\
\hline
\end{tabular}

Fonte: Site TSE (www.tse.jus.br)

Também devemos destacar que há mais mulheres com acesso ao ensino superior do que homens, o que revela uma situação similar aos dados do mercado de trabalho: as candidatas têm mais anos de estudo do que seus colegas homens. Mesmo tendo uma formação educacional mais qualificada, as mulheres ainda encontram muita dificuldade em ter sucesso na vida pública. Destaque para o percentual de homens (25,5\%) com ensino médio, contrastando com a alta escolarização das mulheres (100\%). Os dados do RS não diferem do quadro nacional, o que demonstra o quanto a representação política brasileira é elitizada. 
Sociologias, Porto Alegre, ano 17, no 39, mai/ago 2015, p. 370-402

Tabela 8. Distribuição Gênero x Profissão

\begin{tabular}{l|c|c|c|c}
\hline \multirow{2}{*}{ Profissão } & \multicolumn{2}{|c|}{ Homens } & \multicolumn{2}{c}{ Mulheres } \\
\cline { 2 - 5 } & $\mathbf{N}$ & $\%$ & $\mathbf{N}$ & $\%$ \\
\hline Advogado(a) & 13 & $27,6 \%$ & 01 & $12,5 \%$ \\
\hline Professor(a)/Historiador(a)/Cientista Social & 05 & $10,6 \%$ & 06 & $75 \%$ \\
\hline Médico(a)/Psicólogo(a) & 03 & $6,4 \%$ & 01 & $12,5 \%$ \\
\hline Engenheiro/Arquiteto/Empresario & 06 & $12,8 \%$ & - & - \\
\hline Profissionais mídia/Artista & 03 & $6,4 \%$ & - & - \\
\hline Agricultor & 03 & $6,4 \%$ & - & - \\
\hline Metalúrgico/Sapateiro & 03 & $6,4 \%$ & - & - \\
\hline Outros ${ }^{2}$ & 05 & $10,6 \%$ & & \\
\hline Não Informada & 06 & $12,8 \%$ & - & - \\
\hline Total & 47 & $100 \%$ & 8 & $100 \%$ \\
\hline
\end{tabular}

Fonte: Site Assembléia Legislativa do RS (http://www.alergs.gov.br/)

Quanto às profissões, encontramos uma concentração de mulheres dedicadas à área da educação, enquanto os homens se distribuem por diferentes ocupações profissionais, com destaque para a advocacia.

Em relação à trajetória política, constatamos que as oito eleitas não são novatas no campo político eleitoral: cinco estavam se candidatando à reeleição ao cargo e três já eram vereadoras, sendo que uma dessas já havia sido deputada estadual ${ }^{10}$. Das eleitas, três entraram na política por herança familiar: Silvana Covatti; Maria Helena Sartori e Juliana Brizola. Esta última herdeira política do avô e as outras duas, entraram na política institucional pelas mãos de seus maridos.

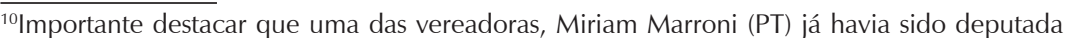
estadual por dois mandatos, mas no pleito de 2010 estava exercendo mandado como vereadora em Pelotas.
} 
Em 2006, a professora Silvana Covatti (PP) elegeu-se deputada estadual pela primeira vez no rastro eleitoral do seu marido, Vilson Covatti, que possui longa carreira política ${ }^{11}$ e postulava uma vaga na Câmara dos Deputados, e com quem fez parceria. Passados quatro anos, a "dobradinha eleitoral" se repetiu e ambos foram reeleitos. De acordo com informações de sua página pessoal, Silvana sempre acompanhou o marido na política, atuando "nos bastidores" e, a partir de um determinado momento, decidiu se candidatar.

Já Juliana Brizola (PDT), advogada e a segunda mulher mais votada, é neta do ex-governador do Rio Grande do Sul e do Rio de Janeiro, Leonel Brizola, e sempre usou o capital político do avô em suas campanhas ${ }^{12}$. Foi eleita vereadora de Porto Alegre em 2008 com excepcional votação. A expressiva votação para vereadora somada à herança familiar e à militância na Juventude Socialista do PDT, da qual foi presidente estadual, contaram para o convite para o cargo de secretária municipal da Juventude na primeira gestão de José Fogaça na Prefeitura de Porto Alegre, quando realizou a $1^{\underline{a}}$ Conferência Municipal da Juventude.

Maria Helena Sartori (PMDB), professora aposentada, é esposa de José Ivo Sartori que possui longa carreira política e que, até 2012, exerceu mandato de prefeito de Caxias do Sul/RS ${ }^{13}$. Há 40 anos filiada ao PMDB,

\footnotetext{
${ }^{11}$ Vilson Covatti começou sua carreira política como vereador no município de Frederico Westphalen/RS (1982-1986), de deputado estadual/RS (1995-1999/1999-2003/2003-2007) e de deputado federal (2007-2011/2011-2015), sempre pelo PP. Nas eleições de 2006, quando concorreu pela primeira vez à Câmara, lançou sua esposa para deputada estadual e desde então o casal concorre em "dobradinha" e em ambas as eleições eles foram bem sucedidos.

${ }^{12} J u l i a n a$ não é a única neta de Brizola que construiu carreira política, possui mais dois irmãos: Carlos Brizola (Brizola Neto) deputado federal (2007-2011) e de Leonel Brizola Neto, vereador do Rio de Janeiro (2009-2013).

${ }^{13}$ José Ivo Sartori iniciou sua carreira como vereador em Caxias do Sul/RS em 1976, foi eleito deputado estadual por cinco mandatos (a partir de 1982) e deputado federal (2002) cargo que abdicou ao ser eleito prefeito de Caxias do Sul/RS (2004-2008/ 2008-2012). Recentemente o PMDB homologou a candidatura de Sartori para o Governo estadual em 2014.
} 
Sociologias, Porto Alegre, ano 17, no 39, mai/ago 2015, p. 370-402

somente em 2002, Maria Helena concorreu à deputada estadual, quando obteve 26.330 votos e ficou como suplente; mas já em 2003, assumiu a titularidade permanecendo na Assembleia Legislativa até o último ano da legislatura. Em 2006, foi Líder do Governo Germano Rigotto ${ }^{14}$. Foi presidente estadual do PMDB Mulher do Rio Grande do Sul e atualmente é vice-presidente nacional do PMDB Mulher na região sul do Brasil. Além de Silvana Covatti (PP) e Maria Helena Sartori (PMDB), outras três candidatas buscavam a reeleição: Zilá Maria Breitenbach (PSDB), Stela Farias e Marisa Formolo, ambas do PT.

A pedagoga Zilá Breitenbach (PSDB) iniciou sua carreira política como Vice-prefeita de Três Passos/RS, tornando-se Prefeita por dois mandatos (1997-2000/2001-2004). Em 2007, Zilá chega ao parlamento gaúcho pelo PSDB, pela primeira vez, com 25.106 votos, quando também exerceu o cargo de Líder do Governo Yeda Crusius. Passados quatro anos, reelege-se deputada estadual. Sua carreira pode estar relacionada à atuação na política municipal, especialmente como Secretária da Educação e da Saúde, e ao sucesso de seus mandatos como prefeita, quando implementou uma gestão participativa com a comunidade, parceria que gerou projetos, conferindo-Ihe destaque nacional como Prefeita Empreendedora ${ }^{15}$.

Na bancada feminina do PT, duas deputadas foram reeleitas, uma era estreante no cargo e a outra candidata voltava a ocupar uma vaga na Assembleia Legislativa. A petista Stela Farias, professora estadual, militou na Pastoral da juventude e no sindicato dos professores públicos estaduais (CPERS-Sindicato), onde foi dirigente. Tem longa carreira política eleito-

\footnotetext{
${ }^{14}$ As informações constam no site http://pmdb-rs.org.br/scripts/el_deputado.php?id=72, acesso 20 /set 2012).

${ }^{15}$ Site http://deputadazila.com.br/, acesso em 29 jul/2012.
} 
Sociologias, Porto Alegre, ano 17, no 39, mai/ago 2015, p. 370-402

ral: foi vereadora (1992-1996) e prefeita de Alvorada/RS por dois mandatos (1996-2000/2000-2004). Elegeu-se deputada estadual em 2006 e foi reconduzida ao cargo; quatro anos depois, ocupou o cargo de Secretaria Estadual da Administração na atual gestão de Tarso Genro e em março desse ano voltou ao Legislativo.

A parlamentar Marisa Formolo (PT), professora, militou no movimento estudantil, nas organizações de estudantes católicos, fundou o DCE da Universidade de Caxias do Sul (UCS), foi presidente de diretórios e associações e coordenadora do Movimento Nacional dos Direitos Humanos. Sua carreira política eleitoral teve inicio com o cargo de Vice-prefeita de Caxias do Sul (1997-2001). Foi deputada estadual na legislatura 2007-2011 e reeleita no pleito de 2010. Nas eleições de 2012, estava cotada para disputar a Prefeitura de Caxias do Sul, mas acabou abrindo mão de concorrer.

Miriam Marroni (PT), psicóloga especialista em educação, é outra deputada petista que não consta da lista das mulheres com herança política, embora seu marido seja o deputado federal Fernando Marroni (PT). No caso da parlamentar, é necessária uma ressalva: o casal iniciou sua carreira no mesmo período, quando militavam no movimento estudantil e sindical. Possuem carreira solo, mas é importante destacar que atuam em "dobradinha" nos pleitos eleitorais, fator que, sem dúvida, importa muito em termos de gastos de campanha. Miriam elegeu-se vereadora para a Câmara Municipal de Pelotas por quatro mandatos, sendo três consecutivos. Por duas vezes foi eleita deputada estadual. Em 2011 foi Líder do Governo na Assembleia Legislativa e desde 2012 exerce a Secretaria-Geral de Governo de Tarso Genro (PT).

Ana Affonso (PT) ${ }^{16}$, professora municipal, foi eleita para seu primeiro mandato no parlamento estadual em 2010, apesar de estreante na As-

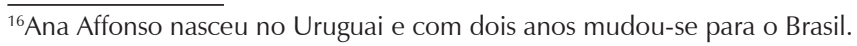

http://dx.doi.org/10.1590/15174522-017003921 
Sociologias, Porto Alegre, ano 17, no 39, mai/ago 2015, p. 370-402

sembléia não era novata na disputa eleitoral. Foi vereadora do município de São Leopoldo/RS por duas legislaturas (2005-2009/2009-2010), chegando a ocupar a Presidência da Câmara dos Vereadores e também foi Secretária Municipal. Iniciou sua militância nos movimentos sociais e da juventude, foi presidente do Sindicato dos Professores de São Leopoldo (2001 - 2003), além de ter sido Diretora de escola. Em 2011, assumiu a vice-presidência estadual do Partido dos Trabalhadores no RS.

Nessa breve trajetória política das candidatas vitoriosas, merece destaque a militância das eleitas. Dentre as oito parlamentares, apenas duas não iniciaram sua carreira através da militância, as demais militaram em: movimento estudantil (2); núcleos partidários - juventude e mulher (2); movimento jovem e sindical (2). Importante relembrar que três delas (Covatti, Brizola e Sartori) possuem herança familiar no campo político.

Do ponto de vista da base eleitoral, Juliana Brizola tem em Porto Alegre seu principal vínculo, sendo a exceção entre as deputadas eleitas. Todas as outras construíram suas carreiras em cidades do interior do Rio Grande do Sul: três são oriundas de duas importantes cidades, Caxias do Sul e Pelotas, ambas com mais de 200.000 eleitores; duas habitam municípios da região metropolitana de Porto Alegre, Alvorada e São Leopoldo, e as duas restantes construíram suas carreiras em pequenos municípios distantes da capital do Estado, Frederico Westphalen e Três Passos. Para chegar à Assembleia Legislativa, com raras exceções, é necessária uma carreira bem sucedida para além do município de domićílo eleitoral do candidato, fator que justifica em muito a "idade madura" das parlamentares.

Outra variável que ajuda a traçar o perfil político das candidatas eleitas é a filiação partidária. Embora o tempo de filiação não seja divulgado por todas as parlamentares, é possível afirmar que todas elas estavam filiadas ao mesmo partido há 10 anos ou mais. Todas as oito deputadas estaduais eleitas em 2010 também se mantiveram fiéis ao partido sele- 
Sociologias, Porto Alegre, ano 17, no 39, mai/ago 2015, p. 370-402

cionado para construir suas carreiras políticas. A longa carreira da maioria das mulheres demonstra alto índice de fidelidade partidária, independente da posição ideológica do partido.

A partir das variáveis analisadas, é possível sintetizar os traços em comum entre as oito candidatas eleitas em 2010: casadas, acima de 45 anos, escolaridade elevada, militantes e com alto índice de fidelidade partidária e, na maioria, originárias do interior do Estado e de cidades de porte médio ou grande.

Em relação à trajetória política dos 47 candidatos eleitos deputados estaduais, merece destaque o número de candidatos reeleitos: 32 candidatos não eram estreantes na carreira parlamentar estadual ${ }^{17}$. Entre os 14 candidatos eleitos para o primeiro mandato, 10 deles já possuíam mandatos anteriores seja como vereador, prefeito ou deputado federal. Apenas quatro candidatos estavam iniciando mandato legislativo, mas não eram desprovidos de experiência no campo da política: dois são do PT, João Edegar Pretto, militante do MST, assessor parlamentar e Altamir Tortelli com importante militância sindical e cargo de liderança na CUT; Lucas Redecker (PSDB) foi candidato a vereador, prefeito e assessor parlamentar; e José Paladini (Catarina), com forte trajetória de militância em movimentos sociais/ estudantil, alcançou votação importante para vereador no município de Pelotas em $2008^{18}$.

Três dos deputados novatos, embora atuem em campos políticos antagônicos, possuem trajetória política similar, baseada em herança política herdada dos pais: João Edegar Pretto (PT), Lucas Rendecker (PSDB) e Marcelo Moraes (PTB) são filhos de políticos com carreiras marcantes na política gaúcha. Edegar Pretto é filho de Adão Pretto (PT), deputado

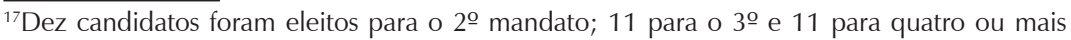
mandatos.

${ }^{18}$ Apesar da expressiva votação, José Paladini não obteve a vaga à Câmara de Vereadores em função da baixa votação do partido pelo qual concorreu naquele pleito - PCdoB.
} 
estadual e federal por cinco mandatos consecutivos falecido em 2009. Edegar possui trajetória similar ao pai, marcada por uma identidade com as lutas dos movimentos sociais, particularmente o Movimento de Pequenos Agricultores (MPA) que ajudou a fundar ${ }^{19}$. Lucas Redecker, filho do ex-deputado federal Júlio Redecker, parlamentar por quatro legislaturas, falecido em 2007. Filiado ao PSDB, mesmo partido do pai, atuou nos bastidores da política como assessor especial junto ao gabinete da governadora Yeda Crusius. Foi ainda presidente da Juventude Estadual do PSDB/RS. No campo eleitoral, Lucas foi candidato a prefeito e a vice-prefeito de Novo Hamburgo em 2004 e 2008, respectivamente, pelo $\mathrm{PSDB}^{20}$. Marcelo Moraes foi vereador e é filho do deputado federal Sérgio Moraes, filiado ao PTB, partido pelo qual exerceu vários cargos: vereador (1982/90) e Prefeito por dois mandatos (1997/2004) em Santa Cruz do Sul (RS); Deputado Estadual por dois mandatos (1991/6); Deputado Federal cumprindo o segundo mandato $(2007 / 15)^{21}$.

Outro dado interessante trata-se da fidelidade ao partido político selecionado para o exercício da militância. Dentre os 47 homens eleitos deputados estaduais, apenas sete trocaram de partido ao longo da carreira política ${ }^{22}$. Os demais candidatos se mantiveram fieis a um único partido ao longo da sua atuação política. Em relação à construção do capital político que possibilitou a candidatura, os dados são interessantes:

\footnotetext{
${ }^{19}$ Site http://www.edegarpretto.com.br/, acesso em 21 ago/2012.

${ }^{20}$ Site http://lucasredecker.com/, acesso em 22 ago/2012.

${ }^{21}$ Site http://www.camara.leg.br/internet/deputado/Dep_Detalhe.asp?id=527964, acesso 10 jun/2014.

${ }^{22}$ Pedro Westphalen iniciou sua carreira no PFL e migrou para PPB/PP, partido pelo qual foi eleito para três mandatos no parlamento estadual; Luiz Fernando Mainardi iniciou sua vida política no PMDB migrando para o PT nos anos 90; Paulo Odone iniciou a carreira no PMDB e migrou para PPS; Luciano Azevedo migrou do PP para o PPS; Antônio Carlos Gomes saiu do PPS para o PRB que congrega vários pastores; José Sperotto trocou o DEM pelo PTB e, por fim, Catarina migrou do PCdoB para o PSB
} 
Sociologias, Porto Alegre, ano 17, no 39, mai/ago 2015, p. 370-402

28 candidatos eleitos não possuem militância fora do campo partidário; 19 possuem biografia marcada por militância (10 destacam a militância estudantil e nove a militância sindical, classista e/ou movimentos sociais). Sete candidatos eleitos somam outros fatores como herança política familiar e profissão (três estão no primeiro mandato e são novatos na Assembleia Legislativa ${ }^{23}$ e quatro foram eleitos para o terceiro mandato). Assim, torna-se interessante apresentar brevemente a trajetória de cada um dos 47 candidatos mais votados no pleito de 2010.

O PT elegeu 10 candidatos, sete são novatos no legislativo estadual, destes apenas dois não possuíam mandatos anteriores como vereadores ou prefeitos. Nove eleitos construíram suas carreiras políticas alicerçadas na militância em movimentos sociais, estudantil ou sindical ${ }^{24}$. A fidelidade partidária também é um destaque do PT, apenas Luís Fernando Mainardi esteve filiado a outro partido (PMDB), todos os outros construíram suas carreiras políticas militando no Partido dos Trabalhadores.

O PMBD é o segundo partido em número de candidatos eleitos. Os sete eleitos eram candidatos à reeleição, cinco deles tem sua carreira política vinculada à militância estudantil ou sindical.

O PP teve seis candidatos eleitos, apenas um deles está no primeiro mandato como deputado estadual, mas não era novato na política eleitoral, pois já possuía mandato anterior como vereador. Apenas um dos candidatos eleitos tem militância corporativa/sindical em seu currículo.

O PDT elegeu o mesmo número de candidatos do PP, ou seja, elegeu seis parlamentares. Dois são novatos na Assembleia Legislativa, mas já possuíam mandatos anteriores, os demais estão entre o $3^{\text {o }}$ e o $5^{\text {o }}$

\footnotetext{
${ }^{23}$ São eles: João Edegar Pretto, filho do deputado federal Adão Pretto; Lucas Redecker, filho do deputado federal Júlio Redecker (os dois deputados federais falecidos recentemente) e Marcelo Moraes, filho do deputado federal Sérgio Moraes.

${ }^{24}$ Apenas o candidato A. Lindenmeyer não coloca a militância estudantil ou sindical como destaque em seu currículo.
} 
Sociologias, Porto Alegre, ano 17, no 39, mai/ago 2015, p. 370-402

mandato. Nenhum dos seis militou em organizações sociais, estudantis ou sindicais. O PTB também teve seis candidatos vitoriosos nas urnas, dois em primeiro mandato com cargos eletivos anteriores e nenhum deles é militante de movimentos sociais, estudantil ou sindical. Interessante destacar que tanto o PDT quanto o PTB são partidos que disputam a herança trabalhista no RS, mas não possuem candidatos com militância sindical. O PSB elegeu três candidatos, dois deles estavam disputando a reeleição. Todos construíram suas carreiras políticas militando em movimentos estudantis e/ou sociais.

O PSDB não apresenta no RS a mesma força política-eleitoral que possui em outros estados da federação, conseguiu apenas quatro cadeiras no legislativo. O PPS conseguiu manter dois deputados que foram reeleitos, o dado interessante é que os dois haviam trocado de partido.

Três partidos elegeram apenas um deputado - PRB, DEM, PCdoB. Todos os três eram candidatos à reeleição. Os candidatos do DEM e PRB não possuem militância em seus currículos, inclusive militância partidária, mas são profissionais da mídia. Apenas o deputado reeleito pelo PCdoB possui militância política no período da ditadura militar. Dois pontos chamam atenção: (a) a militância em movimentos sociais, estudantis e sindicais aparece com destaque nas biografias dos candidatos eleitos por partidos de esquerda (PT, PSB, PCdoB); o PT é o partido com maior renovação na Assembleia Legislativa.

Assim como as mulheres, a maioria dos homens construiu sua carreira política em municípios do interior do Estado do RS e apenas 13 eleitos têm suas bases eleitorais em cidades da Região Metropolitana de Porto Alegre (RMPA); os demais representam municípios de pequeno e médio porte espraiados pelo interior gaúcho. A partir das variáveis analisadas também é possível sintetizar o perfil político dos 47 candidatos eleitos em 
Sociologias, Porto Alegre, ano 17, no 39, mai/ago 2015, p. 370-402

2010: casados, acima de 45 anos, com alta escolarização, com vínculo partidário e com longa carreira política partidária eleitoral.

O recurso econômico (arrecadação de campanha) é um ponto nevrálgico a todos os candidatos, especialmente no caso daqueles que disputam cargos para o Poder Legislativo. De acordo com a legislação eleitoral brasileira, os próprios candidatos são os responsáveis pela arrecadação de recursos para suas campanhas, bem como pela prestação de contas desses gastos ao Judiciário. Aqueles que já são detentores de mandatos, caso da maioria dos candidato/as do universo analisado, têm mais chances de conseguir apoiadores, enquanto que os novatos enfrentam um desafio a mais que é encontrar financiadores de campanha.

Tomando as declarações ao TRE/RS das 133 candidatas à deputação estadual sobre suas despesas de campanha temos que os seus gastos oscilaram muito. O volume de recursos recebido por essas candidatas variou de zero até $\mathrm{R} \$ 509$ mil reais. Pelos dados apresentados constatamos que a líder em arrecadação, Ana Affonso (PT), não foi a campeã de votos, ficou em 390 lugar. Inclusive, seu gasto-médio por voto foi o mais elevado entre as mulheres - chegou a $\mathrm{R} \$ 13,23$, quando a média das oito candidatas foi $R \$ 6,67 /$ voto. Mesmo oscilando muito o volume de arrecadação entre todas as candidatas, é importante frisar que no grupo das eleitas, as deputadas não tiveram problema em arrecadar fundos para suas campanhas, já que a menor arrecadação ficou em $\mathrm{R} \$ 139$ mil, patamar ainda superior aos gastos de campanha de outros 10 deputados. 
Sociologias, Porto Alegre, ano 17, no 39, mai/ago 2015, p. 370-402

\section{Considerações Finais}

É consenso afirmar que apesar da ampliação da participação feminina nas várias esferas da sociedade, o campo da política ainda é um reduto predominantemente masculino, onde as mulheres têm uma tímida presença. Este fenômeno não se restringe só ao Brasil, mas também é global e bastante visível em outros países da América Latina. Mesmo tendo sido adotadas medidas com a finalidade de reverter essa situação tão desproporcional, o processo de participação das mulheres nas instâncias decisórias tem avançado muito lentamente. Desde 1995, a política de cotas foi introduzida no Brasil, mas por si só não tem sido suficiente para solucionar a histórica desigualdade de poder entre homens e mulheres e não tem conseguido reverter - sozinha - a estrutura arcaica e excludente.

O resultado das eleições legislativas no Rio Grande do Sul em 2010 mostrou que as mulheres continuam com dificuldades para se elegeram, tanto para a Assembléia Estadual como para a Câmara Federal, mesmo com a adoção da lei de cotas e das mudanças aprovadas recentemente. Desde a sua adoção, a grande maioria dos partidos não consegue cumprir a cota mínima dos $30 \%$ e as mulheres continuam enfrentando um conjunto maior de dificuldades quando se lançam à corrida eleitoral.

Apesar desse cenário (quase) desalentador, defendemos que um outro olhar também deve ser lançado: observar aquele/as que conseguem se eleger. A pouca renovação no âmbito do legislativo estadual é uma marca tanto para os eleitos como para as eleitas no grupo de 55 parlamentares analisados. Ambos os gêneros são oriundos de sólidas carreiras políticas, iniciadas na esfera local - vereança ou prefeitura - e possuem uma longa trajetória de militância (sindical ou estudantil ou partidária). Portanto, os 47 homens e oito mulheres que se elegeram em 2010 são profissionais da política, com carreiras bem estruturadas e experiências anteriores. Esta 
condição é tão importante, que parece ser mais definidora da vitória do que o montante dos recursos financeiros ou a herança política.

Os dados analisados corroboram nossas hipóteses, pois as candidaturas vitoriosas não apresentam distinções significativas em função do gênero. Além disso, as candidatas vitoriosas à deputação estadual possuem capital político que aproxima sua carreira das carreiras masculinas. A partir disso podemos inferir que eles/elas estão revelando o caminho da maturidade do regime democrático no Brasil.

Rosangela Marione Schulz - professora adjunta no Instituto de Sociologia e Política (ISP) da Universidade Federal de Pelotas (UFPel), Coordenadora Adjunta do Mestrado em Ciência Política e Coordenadora da Especialização em Sociologia e Política. \rosangelaschulz@gmail.com

Maria Lúcia Moritz - professora adjunta do PPG Ciência Política UFRGS.

M marialuciamor@ig.com.br

\section{Referências}

1. ARAÚJO, Clara. Gênero, poder e política: rupturas e diálogos com a representação institucional. In: MINELLA, Luzinete Simões. Saberes e fazeres de gênero - entre o local e o global. Florianópolis: UFSC, 2006, p. 207-223.

2. ARAÚJO, Clara. Condicionantes institucionais das políticas de cotas. In: SOARES, G.; RENNÓ, L. (orgs.). Reforma Política: lições da história recente. Rio de Janeiro: FGV, 2006.

3. ARAÚJO, Clara. Gênero e acesso ao poder legislativo no Brasil: as cotas entre as instituições e a cultura. Revista Brasileira de Ciência Política, Brasília, n. 2., julho-dezembro de 2009, p. 23-59.

4. ARAÚJO, Clara e BORGES, Doriam. O "gênero", os "elegíveis" e os "não-elegiveis": uma análise das Candidaturas para a Câmara Federal em 2010. In: ALVES; PINTO; JORDÃO, Mulheres nas eleições 2010. São Paulo: ABCP/SPPM, 2012, p.337 - 385.

5. ARAÚJO, Clara. Cotas femininas e financiamento de campanha. In: Cadernos Adenauer Ano 14, n.13, 2013, p. 11-30.

6. ARCHENTI, Nélida; TULA, Mária Inés. (Eds.). Mujeres y política en América Latina: sistemas electorales y cuotas de género. Buenos Aires: Heliasta, 2008. 
Sociologias, Porto Alegre, ano 17, no 39, mai/ago 2015, p. 370-402

7. CÂMARA DOS DEPUTADOS. Disponível em: http://www2.camara.gov.br/. Acesso em 12 abr. 2011.

8. LEMOS, Leany B., MARCELINO, Daniel; PEDERIVA, João H. Porque dinheiro importa: a dinâmica das contribuições eleitorais para o Congresso Nacional em 2002 e 2006. Opinião Pública, Campinas, Vol.16, n.2, novembro, 2010, p. 366 $-393$.

9. MIGUEL, Luis Felipe e BIROLI, Flávia. Práticas de gênero e carreiras políticas: vertentes explicativas. Estudos Feministas, Florianópolis, 18(3), set./dez. 2010, p. 653-679.

10. SACCHET, Teresa. Partidos políticos e sub-representação feminina: um estudo sobre recrutamento legislativo e financiamento de campanhas no Brasil. In: PAIVA, D.; BEZERRA, H.D (orgs.). Mulheres, política e poder. Goiânia: Cânone Editorial, 2011.

11. SACCHET, Teresa e SPECK, Bruno. Financiamento eleitoral e representação política: o peso do dinheiro e o desequilíbrio de gênero nas esferas legislativas. In: Congresso da ANPOCS, Caxambu, 2010.

12. SACCHET, Teresa e SPECK, Bruno. Dinheiro e sexo na política brasileira: financiamento de campanha e desempenho eleitoral em cargos legislativos. In: ALVES; PINTO; JORDÂO. Mulheres nas eleições 2010. São Paulo: ABCP/SPPM, 2012, p.417-452.

13. SPECK, Bruno e SACCHET, Teresa. Patrimônio, instrução e ocupação dos candidatos: uma análise das candidaturas de mulheres e homens nas eleições gerais de 2010 no Brasil. In: ALVES; PINTO; JORDÃO. Mulheres nas eleições 2010. São Paulo: ABCP/SPPM, 2012, p.167-206.

14. SAMUELS, David. Financiamento de campanha e eleições no Brasil: o que podemos aprender com o caixa um e propostas de reforma. In: BENEVIDES, M. V. et al. (org.). Reforma Política e Cidadania. SP: Ed. Fund. Perseu Abramo, 2005, p. $364-391$.

15. SCHMIDT, G. e ARAÚJO, C. The Devil'in the details. Open list voting and gender quotas in Brazil and Perú. Paper apresentado no XXV Congresso da LASA, Las Vegas, outubro de 2004.

16. TRIBUNAL REGIONAL ELEITORAL - RS (TRE/RS). Disponível em: http:// www.tre.gov.br. Acesso em 12 mar. 2011.

17. TRIBUNAL SUPERIOR ELEITORAL (TSE). Disponível em: http://www.tse.gov. br. Acesso em 15 mar. 2011.

Recebido em: 08/09/2014

Aceite final: 12/11/2014

http://dx.doi.org/10.1590/15174522-017003921 